\title{
Primary squamous cell carcinoma of the thyroid-case report of a rare disease
}

Lévay Bernadett ${ }^{1}$, Oberna Ferenc ${ }^{1}$, Kiss Alexandra $^{1}$ and Tóth Erika ${ }^{2}$

${ }^{1}$ National Institute of Oncology, Multidisciplinary Head and Neck Cancer Center, Hungery.

${ }^{2}$ National institute of Oncology, Tumor Pathology Center, Surgical and Molecular Pathology Department, Hungery.

Corresponding Author: Lévay Bernadett, National Institute of Oncology, Multidisciplinary Head and Neck Cancer Center, Hungery.

Received date: November 16, 2020; Accepted date: November 30, 2020; Published date: December 24, 2020

Citation: Bernadett L., Ferenc O., Alexandra K. and Erika T., (2020) Primary squamous cell carcinoma of the thyroid-case report of a rare disease J. Endocrinology and Disorders 4(2) DOI:10.31579/2640-1045/057.

Copyright: $\odot$ 2020, Lévay Bernadett, This is an open access article distributed under the Creative Commons Attribution License, which permits unrestricted use, distribution, and reproduction in any medium, provided the original work is properly cited.

\section{Abstract}

Introduction: Primary squamous cell carcinoma (SCC) of the thyroid gland is a very rare entity. The prognosis is very poor with a short survival time. The aim of this article is to report a case of a SCC of the thyroid gland in a 68 -year-old woman, emphasizing how complicate is the operation and the adequate treatment of this disease.

Case Report: A 68-year -old woman presented with rapidly growing neck mass with hoarseness and compressive symptoms. Physical examination revealed a hard fixed tumor with right sided vocal cord palsy. Histopathological result confirmed the diagnosis of SCC of the thyroid. PET/CT scan excluded the possibility of other primary malignancies. A surgical intervention was performed, however the patient died in the middle of the palliative radiation therapy.

Conclusion: SCC of the thyroid gland is a great challenge for the surgeon and also for the multidisciplinary team to come up with the best treatment option which is suitable for the patient due to its unfavorable prognosis.

Key Words: squamous cell carcinoma; thyroid gland

\section{Introduction}

Primary squamous cell carcinoma (SCC) of the thyroid gland is a very rare entity less than $1 \%$ of all primary carcinomas of the thyroid gland. Only a few cases are reported in the literature [1]. This malignancy has a very aggressive behavior and a very poor prognosis, the median survival time is less than 6 months after the time of diagnosis [2]. The optimal treatment would be the surgical resection followed by adjuvant radiotherapy and chemotherapy. The aim of this article is to report the case of a SCC of the thyroid gland in a 68-year-old woman, emphasizing how complicate is the operation and the adequate treatment of this disease [3].

\section{Case Report}

A 68-year-old female patient with a 35-year 2 months of history of a large mass on the anterior neck was admitted to the National Institute of Oncology due to progressive dyspnea, hoarseness and swallowing problems. In her previous medical history hypertension, diabetes and GERD appeared. With physical examination a fixed hard neck mass was palpable in the thyroid gland mostly on the right side with right sided lymphadenopathy. Laryngoscopy showed a right sided vocal cord palsy. The neck and chest CT showed a huge solid mass in the thyroid region dislocating and compressing the trachea, which reached the superior mediastinal region. (Figure 1.)

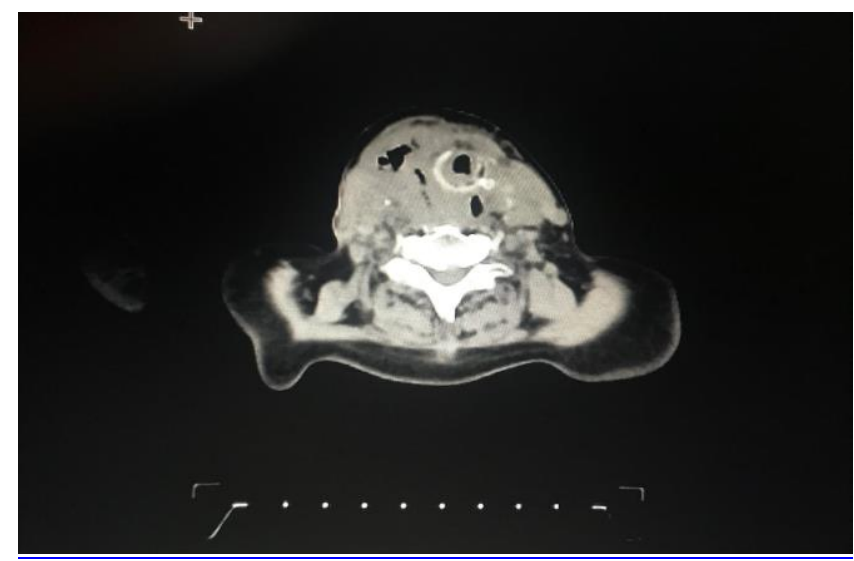

Figure 1. Neck CT scan shows a large mass dislocating and compressing the trachea 
Thyroid ultrasound was performed revealing a mass of the right lobe measuring $8.3 \times 5.8 \times 5.0 \mathrm{~cm}$ with retrosternal extension, and with a $1.8 \times 1.7 \mathrm{~cm}$ calcified mass in the middle of the lobe. The ultrasound also showed the presence of enlarged metastatic lymph nodes in the right lateral neck regions. Fine needle aspiration (FNA) cytology was performed two times, which showed squamous cell carcinoma with metastatic lymph nodes in the lateral neck region. Core biopsy was taken with the result of squamous cell carcinoma showing CK5, p40 coexpression. Oesophagoscopy was unremarkable. The patient was prepared for operation. A paratracheal and modified lateral neck dissection on the right side of the neck were performed. Regarding the prominent extra capsular invasion, only an extended R1 resection could be done instead of total thyroidectomy. The tumor infiltrated the trachea, esophagus and the surrounding soft tissues. The larger part of the tumor was removed from the trachea with shaving technique, the recurrent nerves could not be identified on either side. The patient's hospitalization was uneventful and was discharged on the fourth postoperative day.

\section{Histology and molecular pathology analysis of the resection specimen:}

Histological examination showed the presence of well differentiated invasive SCC with keratinization, infiltrating mainly the right lobe of the thyroid gland (Figure 2, Figure 3). The tumor showed typical immunophenotype, it was CK5 and p40 positive. Large areas of fibrosis with calcification and foci of necrosis were observed in the central area of the tumor. There were no sign of other component (e.g. papillary area) suggestive of primary thyroid cancer. Out of the 40 resected lymph nodes, 10 showed metastasis of the SCC. Extra nodal extension of the tumor was present on multiple lymph node levels.

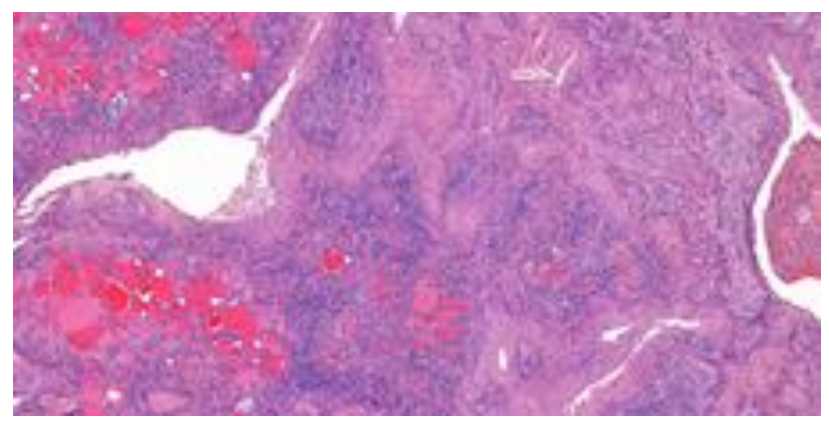

Figure 2. Conventional squamous cell carcinoma infiltrating the thyroid gland.

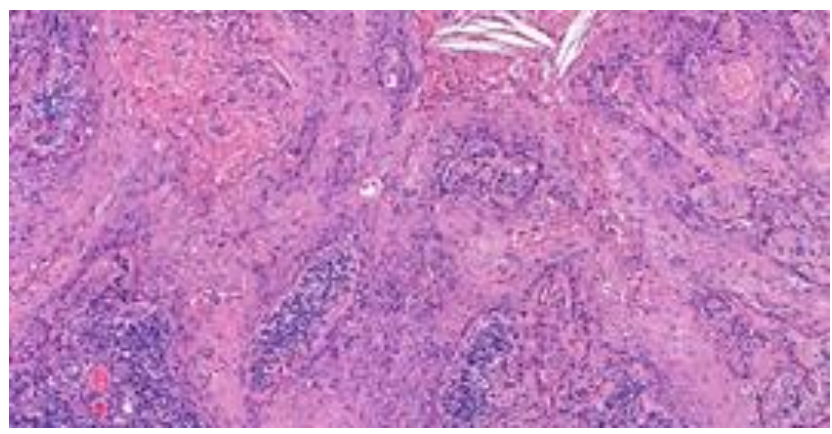

Figure 3. High power photo of the squamous cell carcinoma. Focal keratinization can be seen.

Biomarker analysis showed prominent PD-L1 expression. PD-L1 expression was detected with DAKO 22C3 PharmDx kit according to the manufacturer instructions. $40 \%$ of tumor cells showed complete or partial PD-L1 expression, tumor proportion score (TPS) was 40\%. Combined positive score (CPS) was 50. Detailed molecular analysis was also performed using Oncomine Focus Assay on IonTorrent S5 platform. The kit contains the following genes. Oncomine focus hotspot: AKT1, ALK, AR, BRAF, CDK4, CTNNB1, DDR2, EGFR, ERBB2, ERBB3, ERBB4, ESR1, FGFR2, FGFR3, GNA11, GNAQ, HRAS, IDH1, IDH2, JAK1, JAK2, JAK3, KIT, KRAS, MAP2K1, MAP2K2, MET, MTOR, NRAS, PDGFRA, PIK3CA, RAF1, RET, ROS1, SMO Oncomine focus copy number: AKT1, ALK, AR, BRAF, CCND1, CDK4, CDK6, EGFR, ERBB2, FGFR1, FGFR2, FGFR3, FGFR4, KIT, KRAS, MET, MYC, MYCN, PDGFRA, PIK3CA Oncomine focus gene fusion: ABL1, AKT3, ALK, AXL, BRAF, EGFR, ERBB2, ERG, ETV1, ETV4, ETV5, FGFR1, FGFR2, FGFR3, MET, NTRK1, NTRK2, NTRK3, PDGFRA, PPARG, RAF1, RET, ROS1. Both DNA and RNA based sequencing were performed. After macro-dissection tumor cell content of the sample was $60 \%$. We detected NRAS exon 3 mutation, p.Gln61Lys, c. 181C>A, with
$24.32 \%$ mutant allele ratio and amplification of EGFR gene with copy number 17,18 .

The patient was referred to multidisciplinary tumor board before further therapy. Regarding the PDL-1 positivity immunotherapy and radiotherapy was recommended. On the 34th postoperative day, urgent tracheotomy was needed due to heavy dyspnea. PET/CT scan was recommended which showed a huge mass between the upper parajugular region down to the anterior mediastinum surrounding the trachea and infiltrating the vessels on both sides of the neck and reaches the hypopharynx and larynx as well and also ruled out the possibility of other primary malignancies. Lymphadenopathy was observed in the mediastinum and on both sides of the neck. FDG dense nodules were found in the lungs on both sides, as well as in the thoracal vertebrae, in the sacrum and in the pelvis. Lymphadenopathy was detected in the cervical, right hilar and right inguinal region. Multidisciplinary tumor board offered palliative radiotherapy with 10x3 Gray. Patient received $5 \times 3$ Gray radiation, when severe renal failure developed, which ended up with dialysis. She was admitted to the uro-oncology department. Due to her physical status, active oncotherapy could not be carried out. After 5x3 Gray palliative radiation the patient died. 


\section{Discussion}

A primary SCC of the thyroid is rare, representing $<1 \%$ of all primary thyroid carcinomas. It is more common in females. Due to its rarity, only few cases are reported in the international literature. It is considered to be highly aggressive tumor with a poor prognosis [4]. SCC affects usually older patients between the fifth and sixth decade and is usually associated with a history of goiter. In the majority of cases, the patients present at the time of diagnosis with a rapidly enlarged neck mass, followed by symptoms of infiltration and compression of adjacent neck structures (dyspnea and hoarseness). Infiltration of cervical lymph nodes may or may not be present [5-6].

Clinically anaplastic thyroid carcinoma is the main differential diagnosis. In our case histologically very evident squamous cell differentiation was seen, we could not detect any other component after cut up the whole specimen. SCC is of unknown etiology, as the thyroid gland normally lacks squamous epithelium. Several theories have been suggested regarding its etiology. However, three theories have been popularized. First, the embryonic nest theory suggests that the squamous cells are derived from the remnants of thyroglossal duct or the epithelium of the thymus [7]. Secondly, the metaplasia theory suggests that these cells present as a result of Hashimoto's thyroiditis [8]. Thirdly, the dedifferentiation theory suggests that existing papillary, follicular, medullary or anaplastic carcinoma dedifferentiate into SCC [9]. In everyday practice squamous differentiation is most frequent in papillary thyroid carcinoma but in these cases the papillary component can be detected. However we have not seen any papillary area in the tumor in our case and the results of molecular analysis were not suggestive of papillary thyroid cancer also. Molecular pathological analysis showed NRAS exon 3 mutation, p.Gln61Lys, c.181C >A which is most frequent in follicular thyroid tumors and very rare in squamous cell carcinomas of any region. However amplification of EGFR gene is frequently seen in head and neck squamous cell carcinomas, NRAS mutation is extremely rare, which can underline the real thyroid origin of our case [10].

The optimal treatment of primary thyroid SCC is surgical excision with adjuvant radiotherapy and chemotherapy. However, many studies suggest that it is relatively radio-resistant and has poor response to chemotherapy, leaving complete surgical excision the only chance of prolonging survival of these patients $[11,12]$. Nowadays immune-oncological therapies, like anti-PD1 and anti-PD-L1 therapy, are a very successful therapeutic options for head and neck squamous cell carcinomas. Booya et al. reviewed 10 cases on SCC $n$ the thyroid and discussed that p21, MIB-I, and p53 are overexpressed in primary squamous cell carcinoma of the thyroid and may have relevance to early diagnosis of SCC in the patient [13]. In our case PD-L1 expression was high both on tumor cells and on tumor infiltrating lymphocytes which predict good response to these drugs. Unfortunately the rapid progression of the disease prevented any further therapies. Patients with primary thyroid SCC have a very poor prognosis and the main cause of death is direct invasion or compression of the trachea. Cho et al. recently performed a systematic review and individual participant data meta-analysis regarding primary SCC of the thyroid gland. According to this meta-analysis (89 patients), the mean age of diagnosis was 63 years (range, 24-90), a female preponderance (M: F $=1: 2$ ) was noted and the commonest complaint was the anterior neck mass. It was noted that predictability of diagnosis with fine needle aspiration cytology was accurate in less than one-third of the patients and more than half of cases had been diagnosed as papillary thyroid carcinoma or were non-diagnostic [14]. Complete surgical resection (Ro) of the tumor would be the only significant prognostic factor on multivariate analysis, and the benefit of adjuvant treatment was not proved. Moreover, the prognosis of these patients was very poor (only $20 \%$ of 3 year survival rate) $[15,16]$.

\section{Conclusion}

SCC of the thyroid gland is a very rare and aggressive tumor with poor prognosis. Complete surgical resection (Ro) of the tumor is the only significant prognostic factor, whereas efficacy of adjuvant treatment (chemo- and radiotherapy) remains controversial in the international literature. A fatal outcome is usually a result of its complications, due to loco-regional spread of the disease to adjacent organs and structures [17, $18]$.

\section{References}

1. B. H. Sun, S. T. Yu, J. N. Ge, and S. T. Lei, (2020) Primary squamous cell carcinoma (PSCC) of the thyroid: A case report and review of the literature. Gland Surg., vol. 9, no. 2, pp. 474477.

2. R. T. Othman, A. M. A. Baizeed, and A. A. Mohammed, (2020) Squamous cell carcinoma of the thyroid gland in an elderly female presenting as a rapidly enlarging thyroid mass. Int. J. Surg. Case Rep., vol. 70, pp. 119-122.

3. B. Raggio, J. Barr, Z. Ghandour, and P. Friedlander, (2019) Primary squamous cell carcinoma of the thyroid. Ochsner J., vol. 19, no. 3, pp. 290-292.

4. S. Yang et al., (2019) Primary Squamous Cell Carcinoma in the Thyroid Gland: A Population-Based Analysis Using the SEER Database. World J. Surg., vol. 43, no. 5, pp. 1249-1255.

5. S. Kallel, R. Kallel, S. Ayadi, and A. Ghorbel, (2018) Primary squamous cell carcinoma of the thyroid associated with papillary thyroid carcinoma and Hashimoto's thyroiditis. Eur. Ann. Otorhinolaryngol. Head Neck Dis., vol. 135, no. 4, pp. 291-293.

6. M.-I.-S. Ibrahim, Y.-R. Jusoh, N.-N. Adam, and I. Mohamad, (2018) Primary Squamous Cell Carcinoma of the Thyroid Gland. Iran. J. Otorhinolaryngol., vol. 30, no. 96, pp. 65-68.

7. A. Wygoda, T. Rutkowski, B. Szcześniak-Kłusek, J. MrochemKwarciak, M. Jędrzejewska, and K. Składowski, (2017) Primary squamous-cell thyroid carcinoma - a successful treatment with five-year follow-up. Endokrynol. Pol., vol. 68, no. 5 , pp. $592-596$.

8. F. Struller, M. Senne, C. Falch, A. Kirschniak, A. Konigsrainer, and S. Muller, (2017) Primary squamous cell carcinoma of the thyroid: Case report and systematic review of the literature. Int. J. Surg. Case Rep., vol. 37, pp. 36-40.

9. M. Del Rosario, C. Dasanu, H. Tsai, and R. Johnson, (2017) Primary squamous cell carcinoma of the thyroid with complete response to radical radiotherapy and concurrent cisplatin-based chemotherapy. BMJ Case Rep. vol. 2017.

10. G. Aaron Hobbs, Channing J. Der, and Kent L. Rossman. (2016) RAS isoforms and mutations in cancer at a glance. $J$ of Cell Science. 129, 1287-1292.

11. V. S. Shenoy, R. A. Rao, P. M. Kamath, V. Prasad, and S. Haseena, (2016) Primary Squamous Cell Carcinoma of Thyroid - A Rare Malignant Goitre. Indian J. Surg. Oncol., vol. 7, no. 4, pp. 467-469.

12. C. Lichiardopol, V. Şurlin, M. C. Foarfă, M. C. Ghiluşi, and S. Bondari, (2016) Primary squamous cell carcinoma of the thyroid: a case report. Rom. J. Morphol. Embryol. Rev. Roum. Morphol. Embryol, vol. 57, no. 2 Suppl, pp. 831-836.

13. A. Booya F, Sebo TJ, Kasperbauer JL, Fatourechi V., (2006) Primary squamous cell carcinoma of the thyroid: report of ten cases. Thyroid. 16(1):89-93.

14. J. K. Cho, S. Woo, J. Park, M. Kim, and H. Jeong, (2014) Primary squamous cell carcinomas in the thyroid gland: an individual participant data meta-analysis. Cancer Med., vol. 3, no. 5, pp. 1396-1403. 
15. R. N. Chavan, B. Chikkala, C. Biswas, S. Biswas, and D. K. Sarkar, (2015) Primary Squamous Cell Carcinoma of Thyroid: A Rare Entity. Case Rep. Pathol., vol. 2015, pp. 1-3.

16. K. Sapalidis et al., (2014) Primary squamous cell carcinoma of the thyroid gland. J. Surg. Case Reports, vol. 2014, no. 12, pp. rju133-rju133, Dec. 2014.

17. J. Zhao, J. Wang, D. Wu, and J. Xiong, (2014) Primary squamous cell carcinoma of thyroid: a case report. Zhonghua er bi yan hou tou jing wai ke za zhi Chinese J. Otorhinolaryngol. head neck Surg., vol. 49, no. 1, pp. 69-70.

18. H. Kleinhans, K. W. Schmid, and T. Verse, (2013) Primary squamous cell carcinoma of the thyroid gland. $H N O$, vol. 61, no. 7, pp. 661-663.
This work is licensed under Creative

Commons Attribution 4.0 License

To Submit Your Article Click Here: Submit Manuscript

DOI: $10.31579 / 2640-1045 / 059$
Ready to submit your research? Choose Auctores and benefit from:

* fast, convenient online submission

* rigorous peer review by experienced research in your field

* rapid publication on acceptance

* authors retain copyrights

* unique DOI for all articles

* immediate, unrestricted online access

At Auctores, research is always in progress.

Learn more www.auctoresonline.org/journals/endocrinology-anddisorders 